\title{
A relação do herói no cinema e nos jogos eletrônicos
}

\author{
Fabian Antunes Silva* \\ Fernando Vugman**
}

\section{Resumo}

Os jogos eletrônicos estão assumindo uma posição cada vez mais importante não apenas como mídia de entretenimento, mas também como objetos culturais amplos e potentes. Nesse artigo, me proponho a iniciar uma discussão acerca da construção do herói nos jogos eletrônicos digitais relacionando-o ao herói no cinema hollywoodiano. A partir daí pretendo pensar sobre as relações entre os públicos dos jogos e os do cinema e quais as formas que eles se relacionam com seus heróis em uma mídia e outra. Dessa forma admitimos que há semelhanças e diferenças; entre elas e principalmente, a questão do desafio, elemento formal dos jogos que se destaca por exigir uma ação e uma habilidade do jogador para que o jogo em si se realize e a trama, se houver uma, possa se desenvolver.

\section{Palavras-chave}

Jogos eletrônicos. Cultura digital. Cinema. Comunicação. Linguagens.

\section{Apresentação}

A apropriação de determinada linguagem de um dispositivo por outro não é novidade alguma. A literatura buscava trazer a palavra falada para um suporte físico, servindo primeiro como continuidade de uma linguagem oral, como receptáculo duradouro do que o humano tinha a dizer, para, com o tempo, ir realizando possibilidades próprias, seja na estrutura gramatical que foi se consolidando, seja na tipologia ou na sua construção espacial. A fotografia se construiu com bases na pintura, para daí descobrir suas próprias possibilidades. O cinema precariamente tratava de trazer a linguagem fotográfica e as linguagens cênicas para a projeção, muito antes de dar conta de uma linguagem própria. Com os jogos eletrônicos, e com outras linguagens digitais de nossa era, a história não foi diferente. Já há algum tempo

\footnotetext{
* Mestrando do Programa de Pós-graduação em Ciências da Linguagem- UNISUL.

** Doutor em Literaturas da Língua Inglesa pela Universidade Federal de Santa Catarina e professor do Programa de Pós-graduação em Ciências da Linguagem - UNISUL.
} 
os jogos eletrônicos vem incorporando alguns elementos do cinema em suas produções, seja na construção de suas narrativas, seja na sua linguagem visual, seja nos meios e custos de produção.

No universo dos jogos eletrônicos é interessante notar a incrível expansão tanto de público, quanto de suportes e possibilidades "in game" que vem se colocando atualmente. Nesse cenário aonde a linguagem do jogo vem tomando nova forma é importante demarcarmos alguns pontos de interesse que nos servirão de base para futuros estudos. Um deles é, a meu ver, a construção do herói nos jogos eletrônicos e a sua relação/herança com o herói do cinema, em especial o herói hollywoodiano figura essa a que os jogos, em sua maioria, devem muito. No ensaio que se segue pretendo pensar como o herói é construído nos jogos eletrônicos e qual a sua relação com o herói típico do cinema americano, quais as motivações e conflitos que são trazidos a ele e como os públicos dessas duas mídias se relacionam com essa figura.

\section{A construção do herói no cinema e nos jogos}

O herói, em sua acepção mais comum, é um arquétipo que pretende reunir em si algumas qualidades necessárias para superar certo desafio que se impõe a ele, representando ainda as qualidades e anseios mais notáveis e estimados pelos outros humanos (qualidades como uma coragem extraodirnária ou uma moral inquestionável), servindo assim como símbolo, ideal e inspiração.

Em termos modernos hollywoodianos, o herói é a figura estimada, repleta de boas virtudes, e que parte em busca da realização de um objetivo geral, que ajudará a determinada comunidade. No entanto, em nossa cultura moderna, atribui-se grande valor à experiência individual, e essa valorização também é encarnada pelo herói moderno. Ao mesmo tempo em que busca ajudar a comunidade, ele busca também a sua própria realização pessoal, seja através de alguma satisfação amorosa, busca por glória ou algum outro objetivo concreto ou abstrato relacionado (como o reconhecimento dos seus pares ou o achado de alguma relíquia). O herói moderno, portanto, tende a reforçar o valor da experiência individual durante sua trajetória, algumas vezes agindo em prol dos homens e mulheres menos heróicos, outras vezes em prol de si próprio, ou como Martín-Barbero afirma: "[...] Os heróis da nova mitologia, mais do que representar a comunidade que encarnam, representam sua própria trajetória, seu esforço para se fazer." (1997, p. 194, grifo nosso).

Segundo Campbell (1997), toda narrativa possui o seu herói; dessa forma é esperado reconhecermos a construção cada vez mais marcante de heróis nos jogos, justamente porque os jogos - em especial aqueles voltados para consoles e computadores - vem se tornando cada vez mais narrativos.

Mas o que motiva o herói? Geralmente um desafio inesperado que, por sua vontade, ou contra ela, ele deve superar a fim de resolver um determinado conflito e ajudar, assim, a uma comunidade ou a alguma pessoa em especial. O herói deve responder ao "chamado", segundo Campbell, que o provoca a sair do seio da sociedade para uma região desconhecida. Tanto no cinema quanto no jogo, esse tipo de esquema dos processos da origem do herói se repete. As motivações, assim como 
os conflitos em causa, podem ser de incontáveis naturezas, no entanto, um esquema básico de "chamado, jornada, retorno" (CAMPBELL, 1997) se desenha em praticamente todos eles, processo esse abreviado pelo tempo de cinema, e ampliado no tempo do jogo. No entanto, a dimensão psicológica do herói, que incluiria seus anseios, medos, recusas e motivações, não é um elemento explorado nos primeiros jogos narrativos. Experiências como "Duke Nuken" ou "Quake", ${ }_{1}^{1}$ embora inserindo "temas", como bem observado por Sarlo quanto aos jogos (SARLO, 1997, pág. 51), ainda não investiam em dilemas internos dos seus personagens principais, desenvolvendo narrativas precárias apenas para dar um pano de fundo que justificasse minimamente os eventos dispostos ao jogador. No entanto, muito dessa simplificação psicológica do personagem não é uma deficiência só dos heróis dos jogos, mas está amplamente difundida no cinema americano. Simplificação essa que reduz o herói a estruturas básicas, conforme as descritas por Wood em seu ensaio "Ideology, Genre, Auteur" (1989, P. 60,61); um arquétipo construído para suportar certos atributos que se mostraram desejáveis na composição do herói americano: o homem heterosexual, branco, provedor, viril, que não possui limites para seus feitos, por exemplo. Construção essa que atende a uma demanda pela manutenção de uma moral e de uma ética americana, baseada na família e na propagação de um "ideal do Lar", dos bons costumes, do trabalho e da ordem, da divisão clara do bem e do mal.

Nos jogos eletrônicos atuais, a construção básica do herói não foge, de modo geral, ao modelo hollywoodiano disseminado. As razões disso, a princípio, são evidentes. A própria produção do jogo como indústria conta com profissionais muitas vezes envolvidos com os dois meios, sejam eles diretores de arte ou escritores e roteiristas, e o seu público imediato é, em sua maioria, o consumidor "médio" que já está acostumado ao estilo de produção hollywoodiana. Da mesma forma, tanto os jogos quanto o cinema acabam bebendo de fontes similares. Os quadrinhos, os desenhos animados e personagens de cartoom, os best sellers, as tendências da moda, a cultura das metrópoles sempre em rápida evolução. Além disso, bebem um do outro (ou mastigam um ao outro), retroalimentando-se (e regurgitando) a ponto de criarem, cada um, as suas tramas e heróis para serem continuadas e retrabalhadas no outro.

Um exemplo claro disso é quando certas produções cinematográficas e jogos são criados simultaneamente, ou seja, sua agenda e desenvolvimento estão vinculados desde o início do projeto. A própria concepção do roteiro do filme se vê tramada no roteiro do jogo onde, de saída, já busca prever cenas e momentos de ação transponíveis para o jogo de forma a facilitar a sua produção, além de integrar com mais naturalidade as duas mídias. Matrix (1999, dir. Irmãos Wachowski), é um dos exemplos mais comuns, visto se tratar de um projeto blockbuster de grandes dimensões. Matrix foi concebido de modo a desdobrar sua história por outros meios que não apenas o cinematográfico, como destaca Jenkis em seu livro Cultura da Convergência (JENKIS, 2009, p. 142). Dessa forma surgiu Enter the Matrix (Shiny Entertainment, 2003), um jogo eletrônico que pretende dar continuidade às narrativas

\footnotetext{
${ }^{1}$ Jogos de tiro em primeira pessoa que enfocam em personagens matando criaturas estranhas, geralmente percorrendo labirintos. Duke Nuken (Apogee Software) foi lançado em 1991 e Quake (Id Software) em 1996.
} 
iniciadas nos filmes, dando cabo de alguns eventos paralelos aos desenvolvidos nas tramas do segundo filme, Matrix Reloaded (2003, Irmãos Wachowski) e do terceiro filme, Matrix Revolutions (2003, Irmãos Wachowski), expandindo assim um pouco mais a história e todo aquele universo ficcional. Segundo Henry Jenkins: "[...] Os outdoors ao fundo das cenas contêm cheat codes que podem ser usados para burlar e destravar níveis no game Enter the Matrix (2003)." (2009, p. 142).

Da mesma forma, foi uma maneira de explorar melhor alguns personagens que eram secundários na trama para o cinema, como Niobe e Ghost. Transformers (2007), dirigido por Michael Bay, Green Lantern (2011), dirigido por Martin Campbell, e a maioria dos filmes de super-heróis, personagens de animação e cartoons (The Smurfs (2011), dirigido por Raja Gosnell e Tintin (2011), de Steven Spielberg hoje são produzidos ao mesmo tempo que os seus jogos. Temos também Avatar (2009), de James Cameron, onde a produção do jogo acabou tendo os modelos de armas e veículos criados pela sua equipe de projetistas incorporados à versão cinematográfica. Não são muitos os exemplos ainda, mas visto que os jogos hoje representam um faturamento maior que a indústria cinematográfica, não é difícil imaginar que haverá certa tendência a tornar "quase tudo jogo", assim como a aproveitar jogos para versões cinematográficas. O filme sobre a heroína dos games, Lara Croft: Tomb Raider (2001) do diretor Simon West e os filmes sobre os mortais lutadores da série Mortal Kombat (1995), dirigido por Paul W.S. Anderson, duas famosas franquias de jogos eletrônicos que viraram película, são outros exemplos dessa retroalimentação. Atualmente não é difícil encontrar filmes que apresentam uma estrutura narrativa muito semelhante ao processo de "passar de fases", tão utilizado pelos jogos eletrônicos. Concentrando-se em cenas de ação, câmeras rápidas, poucos diálogos, e um movimento de crescente dificuldade para o herói ou heroína. São exemplos recentes: Resident Evil Retribution (2012), dirigido por Paul W.S. Anderson e Abraham Lincoln: Caçador de Vampiros (2012), de Timur Bekmambetov.

No cinema, muitas vezes, o herói, o vilão e a trama básica devem ser previamente explicados. Isso se dá porque, geralmente, os produtores consideram o público médio como seu público alvo, ou seja, aquele cidadão que não sabe necessariamente tudo o que tem para saber sobre a trama que decidiu assistir, ou que sabe realmente muito pouco ou nada. Em seus minutos iniciais a projeção procura apresentar a trama e seus personagens de uma maneira sequencial, clara e com tempo adequado para que o público possa aprender o mínimo necessário para o entendimento do que vai se seguir. Ou seja, de maneira geral, um filme americano do tipo "blockbuster", como Resident Evil: Retribution (2012), de Paul W.S. Anderson, elabora um tutorial ${ }^{2}$ básico durante a projeção que pretende instrumentalizar o espectador, seja através da exposição prolongada de determinado personagem, seja com marcações que o distinguam de modo especial, seja com repetições mais frequentes dele durante as primeiras cenas. No caso especial de Resident Evil, o filme se dá ao trabalho de refazer, através de flashbacks, toda a história contada nos filmes anteriores, tentando construir alguma lógica narrativa entre este filme e os anteriores.

2 Tutorial é uma ferramenta de aprendizagem que pretende ensinar passo a passo o funcionamento ou o modo de fazer algo. 
Assim o herói do cinema americano típico é primeiramente introduzido pelas suas capacidades ou maneiras de se colocar diante dos conflitos, que o distinguirão dos seus pares, para depois serem introduzidos numa trama maior, que pode vir a ser apresentada nos momentos iniciais, mas que geralmente está reservada a momentos posteriores na projeção. O filme Sherlock Holmes (2009), de Guy Ritchie é um exemplo desse uso. Sherlock é apresentado em ação já nos primeiros momentos da trama, suas habilidades de luta bem como suas capacidades dedutivas são exploradas inicialmente e, nesse caso em especial, já somos apresentados a três das personagens mais importantes da trama, embora ainda não saibamos com certeza disso. Logo após somos convidados a conhecer as excentricidades dos métodos de pensamento e ação do intrépido detetive e nos são apresentadas, em um nível muito básico, as relações emocionais que os personagens Holmes e seu amigo Watson mantém um com o outro. O vilão é marcado com sombras, olhares sinistros, comportamentos claramente maquiavélicos; dessa forma o filme nos dá instrumentos para que não tenhamos dúvida do lado pelo qual devemos torcer.

No entanto, no desenvolvimento do personagem para o cinema e para os jogos há certos desníveis, uma mudança de "registros" entre as duas figuras que não permitem que encaixemos uma exatamente com a outra. Esses desníveis são causados principalmente pela forma dos meios. Cinema e jogos, embora próximos, possuem uma distância singular quando pensamos nas suas formas de produção, mas muito mais quando pensamos nas suas formas de fruição, ou seja, o modo como os espectadores/jogadores se colocam em relação à obra constituída.

Nos jogos atuais os personagens, a trama e o herói, são muitas vezes tratados de forma similar; no entanto, quando se trata de produções baseadas em filmes, muito do terreno da explicação já foi dado previamente e são comuns os jogos que não se dedicam a explicar com muita profundidade o que afinal está acontecendo. $\mathrm{Na}$ verdade, outra dimensão de explicações se faz necessária, um tutorial, no seu sentido mais autêntico, se faz presente. Trata-se de ensinar a mecânica do jogo ao jogador, seus objetivos, as habilidades do herói e as formas dele se relacionar com os eventos propostos durante o desenrolar do desafio.

Dessa forma, desdobra-se uma primeira diferença entre o herói do cinema e o herói do jogo. $O$ jogador deve saber previamente quais as qualidades e capacidades do herói antes de poder usá-las e assim, com base nessas informações preliminares, o jogador poderá concluir quais desafios aquele herói poderá superar, qual o caminho mais favorável a percorrer e de quais perigos ele deverá se esquivar ou combater para obter sucesso. Se não for assim, o jogador deverá percorrer inúmeras vezes o mesmo caminho, falhando nas suas tentativas, até que consiga adquirir a habilidade necessária para transpô-lo ou então até que deduza outras maneiras de superá-lo, as quais não havia previsto, ou sobre as quais não havia sido ensinado anteriormente. 0 risco é o da frustração e que essa frustração atinja níveis muito altos a ponto de o jogador abandonar o jogo de vez. 


\section{A relação do público com o herói}

Comecemos primeiramente pela própria definição do seu público: o público do cinema é usualmente tratado como espectador, aquele que, numa concepção rasa, assiste a um conteúdo que se desdobra diante dele.

Enquanto isso, o público do jogo eletrônico pretende ser percebido como jogador, ou ainda numa definição mais ampla, como um interagente (ou interator); ou seja, solicita-se do público do jogo uma ação física, ação essa que dará movimento ao jogo e sua narrativa e desafios, ação essa que, se interrompida (seja porque o jogador parou de jogar, seja por sua inabilidade motora), interrompe também o próprio fluxo da narrativa. Além disso, o jogo exige momentos de tomadas de decisão para a superação dos desafios e o desenrolar da narrativa, caracterizando assim, uma parte de inserção do jogador no mundo do jogo através dessas decisões.

Desenham-se assim duas potencialidades importantes no que tange ao jogador. A primeira: a capacidade de jogar de forma satisfatória, dominando as técnicas e as ferramentas de modo a superar os desafios propostos; a segunda: a relação imersiva e interativa do jogador em relação ao conteúdo e ao herói, relação essa que determina, como uma de suas potencialidades, a própria identificação do jogador com o personagem jogado (no sentido de servir-lhe de substituto no ambiente virtual, uma espécie de avatar). Potencialidades essas que diferem enormemente da relação habitual do espectador do cinema.

Fica evidente assim que a relação do público com o herói do cinema transcorre de maneira diferente quando o conhecemos num jogo eletrônico. E essa é a segunda diferença entre o herói do cinema e o herói dos jogos. Essa diferença se dá, conforme anteriormente explicado, principalmente devido à forma de cada mídia. Enquanto o cinema nos propõe uma participação onde nos vemos necessariamente "ao lado", e poucas vezes "no lugar de", nos jogos eletrônicos a proposta é outra. Como já previamente pontuamos, existe uma exigência de participação ativa na trama, que é de natureza física sim, mas também de uma natureza emocional que insiste em não nos deixar de fora da ação onde, embora não possamos realmente mudar o rumo dos eventos pré-programados, somos a força motriz necessária para que eles aconteçam.

A própria identificação do público com a obra é diferente. No cinema não nos identificamos necessariamente com o herói, nem sempre é ele quem nos desperta a atenção ou o afeto. A empatia algumas vezes se dá com os personagens secundários da trama, até mesmo com os antagonistas, porque reconhecemos neles nossos próprios medos, dúvidas, uma certa filosofia de vida que nos agrada, ou até mesmo coisas mais sutis, como um jeito especial no olhar e no falar que nos toca de alguma forma. Esse tipo de empatia pode muitas vezes nos levar, enquanto espectadores, a nos sentirmos totalmente contrariados com o desenrolar da trama, a ponto de enfrentarmos momentos em determinadas narrativas em que, inevitavelmente, torcemos pelo sucesso do antagonista, ou então, pela vida e felicidade do personagem secundário que não teve seu brilho merecido durante a maior parte da projeção. 
Por outro lado, o público do jogo, enquanto jogador, necessariamente se relaciona com o herói. Isso se dá justamente porque o herói, em alguma instância, é a representação virtual do próprio jogador. É a maneira pela qual o jogador pode agir naquele mundo. Embora muitos jogos construam personagens complexos, com motivações, dilemas e conflitos próprios que muitas vezes não criam qualquer relação imediata com o jogador, ainda assim a participação do jogador como aquele responsável pelo desenrolar da ação (seja num desenrolar de eventos engessados ou num mundo aberto com possibilidades mais amplas) o aproxima à figura do herói de uma maneira muito diferente daquela percebida pelo espectador do cinema. 0 resultado é que muitas vezes o herói sugerido se apaga para dar lugar ao herói imaginado, aquele herói simbolicamente estruturado pelo jogador, que passa a ser ele mesmo digitalizado no mundo virtual. É claro que isso não é uma particularidade dos jogos eletrônicos, mas sim uma particularidade de alguns jogos eletrônicos. Da mesma forma, esse tipo de transferência pode funcionar para alguns jogadores enquanto para outros isso não acontece. Poderíamos falar sobre uma disposição diante da obra, disposição essa que também tem eco na relação do público com o cinema. Nem sempre estamos "prontos" para assistir a um drama intenso, ou não estamos com humor apropriado para uma comédia familiar. O fato é que, a disposição do público em relação à obra, a sua receptividade e doação para ela naquele momento, é elemento importantíssimo no resultado da sua relação, aprovação ou desaprovação. Muitos dos efeitos desejados, seja pelo cinema ou pelos jogos, podem muito bem não se realizar se o público não se mostrar disposto.

São as qualidades imersivas e interativas do meio que entram em pauta. Qualidades essas que não são exclusivas dos jogos, mas que no jogo são potencializadas. $O$ fato de o jogador ser levado a sentir-se no mundo do jogo faz com que sua relação com a história, seus personagens e seu herói sejam diferentes daquelas que o espectador tem com as histórias, personagens e heróis da projeção de cinema.

Além disso, as motivações, conflitos e moral dos heróis são muitas vezes assunto secundário ao jogador. Elementos que no cinema acabam sendo muito mais importantes são muitas vezes deixados em segundo plano ou, em outras vezes, são dados ao jogador para que preencha essas lacunas da forma que desejar, num processo de "customização" própria do jogo. No lugar disso, o jogo acrescenta uma dimensão a mais para a fruição da obra, a dimensão do desafio. É no desafio que o jogo passa ao jogador a responsabilidade pelo sucesso ou fracasso do herói e, portanto, a própria responsabilidade pela satisfação ou pela frustração. Demarcamos assim uma terceira diferença entre os heróis do jogo e do cinema.

\section{O desafio do herói, o desafio do jogador}

O desafio é o motor que dá condições para a ascensão do herói, é através do desafio que o mundano pode assumir um novo patamar moral, ou seja, pode superar os limites da sua própria sociedade assumindo uma posição icônica entre os demais, podendo ter suas ações e modos de pensar como exemplo ou meta a ser alcançada. 
De forma similar, o desafio é a proposta do jogo que determina um caminho, metas, obstáculos e recompensas que estimulam o jogador. Como o herói mítico que deve enfrentar uma jornada de transformações, também o jogador é convidado a encarnar sua própria jornada, assumindo parte do "peso" que recai sobre o herói através do espaço digital do jogo.

No cinema, o desafio é resolvido pelo personagem enquanto assistimos ansiosos por cada salto, cada grito, cada armadilha e perigo que se coloca diante dele. Torcemos pelos nossos heróis, desejamos que eles vençam, numa necessidade catársica. Precisamos do prazer da resolução dos conflitos.

No jogo, o desafio se apresenta a uma personagem a qual nos foi dada a tarefa de controlar. Nosso sucesso ou nosso fracasso será o sucesso ou o fracasso do herói, portanto, a frustração que seria a dele passa a ser imensamente a nossa. Se não tivermos habilidades suficientes não poderemos nos equivaler dos desafios propostos no jogo, e a trama muitas vezes não terá seu fim catársico necessário. Nosso herói e nossa trama serão muitas vezes jogados ao limbo, para lá permanecer talvez para sempre. Não é à toa que um dos elementos mais importantes na produção de um jogo é o balanceamento, ou seja, o momento onde os produtores buscam definir os parâmetros de dificuldade para cada momento da história, quais vantagens e desvantagens são apresentadas ao jogador e como dar condições para que ele os vença de forma natural, sem tornar a experiência uma tortura para o jogador.

Um exemplo de jogo que vem frustrando os jogadores é Diablo 3 (2012), da Blizzard Entertainment, sequência da cultuada série Diablo (iniciada em 1996) que foi lançado sob uma maré de expectativas, ansiedades e desejos e que, não de modo surpreendente, desagradou a muitos fãs pelo mundo. O "desastre" de Diablo, segundo a visão de alguns fãs, foi ter desvirtuado alguns dos elementos mais marcantes que atraíram tantos jogadores pelo mundo. Um deles seria o visual sombrio, escuro, com uma trilha sonora tensa e com um nível de desafio que colocava os jogadores em estado de constante atenção. Além disso, segundo as marés de reclamações nos Fóruns oficiais do jogo, os jogadores se queixam das estilizações dos personagens e cenários, bem como do curto tempo da trama principal, deixando muito do ato de jogar como tarefa apenas de coletar itens (do vocabulário dos "gamers" brasileiros: "farmar itens" - corruptela de inglês to farm). O jogo em si conta com uma trama principal, linear, onde o jogador deve encarnar um dos cinco arquétipos propostos: o bárbaro, o monge, a arcanista, o feiticeiro ou a caçadora de demônios; e lutar contra hordas de demônios vindos do inferno para salvar a terra. Embora os produtores do jogo tenham se concentrado em desenvolver as histórias desses heróis, é dada ao jogador a possibilidade de escolher o sexo e o nome do seu personagem. Na trama, a visão do jogador é superior, uma opção própria da série e que foi mantida. Não é preciso muita habilidade para jogar Diablo 3; o personagem é movido a cliques do mouse, atacando alvos da mesma forma. Através do teclado numérico acessam-se algumas habilidades especiais que, de certa forma, definem uma estratégia e modo do jogo. O sistema foi construído com vários níveis de desafio, e no nível "normal", o jogo se apresenta fácil e rápido, dando a oportunidade de conhecer toda a trama principal em algumas horas de partida. A relação com o jogo se dá em dois níveis: no espaço 
fictício da trama, onde o jogador interessado pode seguir o caminho mais rápido ou explorar e encontrar textos que acrescentam novas informações sobre o mundo, novas áreas, desafios extras e objetivos adicionais; e na relação do jogador com outros jogadores, em modo cooperativo online, onde pode construir amizades, inimizades, aprender coisas novas sobre o jogo, superar desafios que não conseguia sozinho ou comercializar itens e, ainda, nos espaços do fórum, onde pode compartilhar estratégias, sugerir mudanças, criticar o sistema e coletar opiniões.

Diablo 3 apresenta uma trama única, linear, com poucas opções de "customização" dos personagens, ainda assim possui apelo ao fator "replay", algo que os jogos vem investindo há algum tempo, ou seja, despertar a vontade do jogador de "jogar de novo". As histórias de cada personagem são bem desenvolvidas e cada arquétipo possui um estilo único de superar os desafios, forçando o jogador a adaptar suas estratégias para cada um dos tipos. Os heróis do jogo partem em uma jornada altruísta pelo bem dos fracos e inocentes, para expurgar o mal eterno que assola $o$ mundo. Eles representam a força, à vontade e a bondade contra um mal muito bem definido. No caminho, não demonstram qualquer hesitação ou medo, servindo como epítomes do herói perfeito. No entanto, não há qualquer urgência ou medo pelo destino do herói, ele terminará sua jornada, isso está dado, e nada o corromperá ou o fará desistir. Ao jogador, só cabe a decisão de continuar a jogar ou parar, mas não formas de desencadear outros eventos, como a vitória do personagem título "Diablo". A relação do jogador com o jogo é notável; alguns fãs recusaram-se a jogá-lo novamente depois de algumas experiências por conta do visual modificado, trilha sonora mais fraca e história curta demais (justificativas tiradas dos Fóruns do jogo); outros antigos e novos jogadores suportaram ou aprovaram as mudanças, parabenizando elementos como a dublagem em português, o nível de desafio e os arquétipos propostos. O que o jogo parece determinar no fim é uma cisão entre defensores e agressores, e o fórum está recheado de exemplos que vão de simples discordâncias até ofensas mais graves e tentativas de desacreditar um ao outro. Isso é interessante porque nos faz notar a imensa participação do mundo do jogo em uma parte significativa da vida de alguns jogadores. Muitos afirmaram ter pedido folga do trabalho, ficado sem dormir e sob o efeito de cafeína e outros estimulantes, para que pudessem aproveitar ao máximo um jogo que esperaram por mais de dez anos. Esse nível de relação com a obra é próprio dos jogos eletrônicos e parece representar bem o tipo de sociedade contemporânea em que vivemos. Sociedade essa onde algumas das interações mais marcantes que temos com nossos pares hoje em dia se dão por meio de aparatos eletrônicos e simulações digitais. Encontramos demonstrações similares de afeto e doação na relação do público com o cinema quando vemos superproduções americanas como a série Harry Potter (2001 a 2011) ${ }^{3}$ e a trilogia Lord of the Rings (2001, 2002 e 2033, dir. Peter Jackson). Os fãs mais aficionados em filas quilométricas, esperando horas antes para garantir seu ingresso, muitos incorporando

${ }^{3}$ Dos oito filmes que compõem a série, os dois primeiros, Harry Potter e a Pedra Filosofal (2001) e Harry Potter e a Câmara Secreta (2002), foram dirigidos por Chris Columbus; o terceiro, Harry Potter e o Prisioneiro de Azkaban (2004), por Alfonso Cuarón; o quarto, Harry Potter e o Cálice de Fogo (2005), por Mike Newell e os últimos quatro, Harry Potter e a Ordem da Fênix (2007), Harry Potter e o Enigma do Príncipe (2009), Harry Potter e as Relíquias da Morte: Parte 1 (2010) e Harry Potter e as Relíquias da Morte: Parte 2 (2011) por David Yates. 
alguns dos personagens mais característicos de cada franquia, travestidos de elfos ou bruxos. No entanto, a forma do jogo que envolve a disputa, o desafio e a possibilidade de explorar variações do jogo, reforça de forma singular esse tipo de relação aficionada. Muitos jogadores mais afoitos dedicam-se a explorar cada canto e cada elemento do jogo, aprender movimentos, desenvolver técnicas, colocar-se na melhor posição dos rankings oficiais.

No entanto, diferente do cinema, a resolução final da trama nem sempre possui uma única possibilidade, e embora a maioria dos jogos esteja construída com base numa única solução, existem alguns outros que dão a possibilidade de fins alternativos que se adequam às escolhas do jogador durante o transcorrer da trama. A série Mass Effect (2008, BioWare) é um exemplo. Um RPG (Role Playing Game) futurista, Mass Effect permite uma customização mais ampla do personagem principal, podendo o jogador tentar criar uma versão virtual de si mesmo, ou então conceber outra aparência entre aquilo com que desejaria parecer-se ou não. Sexo, cor, feições e cortes de cabelo já são elementos modificáveis muito comuns no universo dos jogos, principalmente em jogos do tipo RPG. O universo de Mass Effect é vasto, conta com uma mitologia de seres fantásticos e uma história densa e bem desenvolvida. São inúmeras as possibilidades "in game" para se conhecer mais e mais da trama e subtramas do jogo. Além disso, o sistema de relacionamentos e diálogos favorece a imersão e a interação fazendo o jogador se sentir parte daquele universo de modo a criar um vínculo afetivo com os personagens virtuais controlados pela máquina, tanto quanto teria com um personagem carismático do cinema. O herói em Mass Effect pode ser gentil ou grosseiro, agir com bondade ou maldade, e boa parte de suas decisões no jogo afetam o desenrolar da trama e, consequentemente, podem modificar o final do jogo. Mais ainda, cada decisão tomada nos jogos anteriores afeta os jogos posteriores. Assim, se decido salvar uma companheira do jogo "1", em detrimento de outro, as consequências disso serão desenvolvidas no desenrolar do jogo "1" e também nos jogos " 2 " e " 3 ". É inegável que esse tipo de abordagem transforma 0 herói do jogo num herói muito interessante porque o jogador pode voltar a jogar e escolher diferentes caminhos para conhecer. Um personagem assim pode ser maniqueísta, prático, otimista ou pessimista, ou seja, não está preso a apenas uma estrutura de ação. Pode exercer-se, através da vontade do jogador, de diferentes formas que não só aquela do "herói perfeito". Dessa forma o jogador pode, dentro das possibilidades do jogo, tentar exercer escolhas que tenham mais proximidade com a sua própria forma de ser e ver o mundo.

É claro que ainda estamos nos primeiros passos desse tipo de interação e abertura. Ver esses primeiros jogos exercendo uma narrativa mais densa e uma abertura maior favorece o pensamento positivo de que, um dia, poderemos construir histórias tão densas e dramáticas quanto aquelas que aprendemos a conhecer e a adorar em outras mídias. E que, ainda mais, serão abertas o suficiente para que possamos exercitar inúmeras possibilidades de ação, sejam elas para reforçar o mito de herói perfeito, seja para agirmos como anti-heróis ou nos rendermos até mesmo ao papel do vilão, assumindo o papel do monstro que tantas vezes enfrentamos. As possibilidades são infinitas e creio que o futuro nos reservará ainda gratas surpresas nesse campo tão dinâmico e tão representativo dos movimentos constantes de nossa época. 


\section{Referências}

AARSETH, Espen. Playing Research: Methodological approaches to game analysis. University of Bergen. 2003. Disponível em:

<http://hypertext.rmit.edu.au/dac/papers/Aarseth.pdf>. Acessp em: 23 jun. 2012

ARRUDA, Eucidio Pimenta. Aprendizagens e jogos digitais. Campinas, SP: Alínea, 2011.

BORDWELL, David. Film art, an introduction/David Bordwell, Kristin Thompson. 6th ed. New York: Mac Graw-Hill Higher Education.

CAMPBELL, Joseph. O herói das mil faces. Trad. de Adail Ubirajara Sobral. São Paulo: Pensamento, 1997.

FERNANDES, Anita Maria da Rocha et al. Jogos eletrônicos: mapeando novas perspectiva. Florianópolis: Visual Books, 2009.

GALLOWAY, Alexander. Gaming: essays on algorithmic culture. Eletronic Mediations. v. 18. Minneapolis: Minnesota UP, 2006.

GAMEOLOGY. Disponível em: <http://www.gameology.org/>. Acesso em: 29 jan. 2012.

HUIZINGA, Johan. Homo ludens: o jogo como elemento da cultura. São Paulo: Perspectiva, 2008.

JENKINS, Henry. Cultura da convergência. São Paulo: Aleph, 2009.

JULL, J. Games Telling Stories? a brief note on games and narratives. Game Studies, v. 1, 2001. Disponível em: <http://www.gamestudies.org/0101/juul-gts/>. Acesso em: 31 jan. 2012.

SANTAELLA, Lucia; FEITOZA, Mirna (Orgs.) Mapa do jogo: a diversidade cultural dos games. São Paulo, Cegange Learning, 2009.

SARLO, Beatriz. Cenas da vida pós-moderna: intelectuais, arte e vídeo cultura na Argentina. Trad. de Sérgio Alcides. Rio de Janeiro: Editora UFRJ, 1997.

MARTÍN-BARBERO, Jésus. Dos meios às mediações: comunicação cultura e hegemonia. Rio de Janeiro: UFRJ, 1997.

WOOD, Robin. Ideology, genre, auteur: "Shadow of a doubt". Hitchcock's films revisited. New York: Columbia UP, 1989. p. 288-302 


\section{Title}

The relation between the hero in electronic games and in film

\section{Abstract}

Electronic games have acquired an ever greater importance not only as entertainment media, but also as potent and wide ranging cultural objects. In the present paper we begin a debate on the building of the hero in electronic digital games, while comparing that character to the Hollywood hero. From that starting point, we think the relations between the public of the games and that of cinema, and how each public relates to the hero in one media and the other. We find differences and similarities, and we stress the issue of the challenge, a formal element in games, which is important because it demands action and ability from the player so that the game can happen and the plot, when there is one, can develop.

\section{Keywords}

Electronic games. Digital culture. Cinema. Communication. Languages.

Recebido em 04/10/2012. Aprovado em 16/11/2012. 